\title{
Alessandro Stella, Le Prêtre et le Sexe. Les révélations des procès de l'Inquisition
}

Bruxelles, André Versaille éditeur, coll. « L'Autre et l'Ailleurs », 2009, $204 \mathrm{p}$.

\section{Baptiste Coulmont}

\section{(2) OpenEdition}

Journals

Édition électronique

URL : http://journals.openedition.org/assr/21677

DOI : $10.4000 /$ assr. 21677

ISSN : $1777-5825$

Éditeur

Éditions de l'EHESS

Édition imprimée

Date de publication : 31 décembre 2009

ISBN : 978-2-7132-2218-4

ISSN : 0335-5985

\section{Référence électronique}

Baptiste Coulmont, «Alessandro Stella, Le Prêtre et le Sexe. Les révélations des procès de I'Inquisition », Archives de sciences sociales des religions [En ligne], 148 | octobre-décembre 2009, document 148-124, mis en ligne le 15 novembre 2012, consulté le 21 septembre 2020. URL : http:// journals.openedition.org/assr/21677 ; DOI : https://doi.org/10.4000/assr.21677

Ce document a été généré automatiquement le 21 septembre 2020.

(c) Archives de sciences sociales des religions 


\title{
Alessandro Stella, Le Prêtre et le Sexe. Les révélations des procès de l'Inquisition
}

Bruxelles, André Versaille éditeur, coll. «L'Autre et l'Ailleurs », 2009, $204 \mathrm{p}$.

\author{
Baptiste Coulmont
}

\section{RÉFÉRENCE}

Alessandro STELLA, Le Prêtre et le Sexe. Les révélations des procès de l'Inquisition, Bruxelles, André Versaille éditeur, coll. «L'Autre et l'Ailleurs », 2009, 204 p.

148-124

1 L'historien Alessandro Stella s'intéresse ici à quelques cent quarante procès devant le tribunal de l'Inquisition de Mexico, entre 1530 et la fin du XviII ${ }^{e}$ siècle. Ce sont des procès pour "sollicitation ", c'est-à-dire pour séduction dans le cadre de la confession et ils mettent au centre des hommes (prêtres) ayant eu des relations sexuelles avec des femmes (parfois des religieuses), des hommes ou des enfants. Il s'agissait, pour l'Inquisition, de défendre à la fois le sacrement (la confession) et le célibat des clercs.

2 C'est que la confession oblige à un discours sur la sexualité et devient parfois le contexte d'expression de désirs érotiques ou d'échanges amoureux : elle met en relatif face à face (avec parfois les contraintes de la partition et de la génuflexion) des personnes dotées de ressources inégales (pouvoir d'absolution d'un côté, recherche de l'absolution de l'autre, homme âgé d'un côté, jeunes femmes le plus souvent de l'autre...) Il semble que la mise en discours du sexe se soit, relativement souvent à la vue du nombre de procès conservés, transformée en passage à l'acte.

3 L'auteur a sélectionné, pour le cœur de l'ouvrage, les cas peut-être les plus riches: parce que les procès exigent une autobiographie des inculpés, l'on dispose non seulement du récit de leurs crimes, mais aussi de celui de leur éducation et de leur 
carrière. Le premier chapitre présente le contexte de la sexualité coloniale en NouvelleEspagne, où la conquête s'est accompagnée d'une appropriation des femmes: les prêtres accusés de «sollicitation » sont aussi souvent accusés de viols, de violence voire de meurtre envers des Indiens et des Indiennes. Le deuxième chapitre est centré sur ce qui constitue peut-être un double crime: les amours entre prêtres et religieuses. L'auteur souligne la différence d'avec les affaires impliquant des prêtres de villages indiens. Dans les couvents, point de viols, mais souvent le récit de séductions croisées : il y est bien décrit le "glissement » de la confession vers la liaison amoureuse. Les trois chapitres suivant semblent reliés par le caractère "pervers » des sexualités qui y sont révélées : sadomasochisme ("le glissement de la pénitence du fouet aux attouchements sexuels finissant parfois en rapports sexuels complets n'était pas rare», p. 106), homosexualité (chap. 4) et pédophilie (chap. 5). Les deux derniers chapitres montrent les tentatives de conjugalisation menées par certains prêtres, qui sont toutefois rattrapés par leur ordre ou dénoncés : l'on ne peut alors quitter l'habit sans risquer l'accusation d'apostasie.

4 L'historien semble proposer en introduction un livre hybride. Cette introduction ne présente pas que les archives utilisées, la problématique de l'ouvrage, elle comporte aussi plusieurs pages sur les scandales pédophiles récents au sein de l'Église catholique, en Amérique du nord et en Europe ainsi que sur les accusations visant Tony Anatrella et sur quelques déclarations du pape Benoît XVI. Il faut peut-être comprendre que l'auteur souhaite lier, par delà trois siècles, ces scandales entre eux et donner ainsi une actualité à son ouvrage.

5 S'il fallait exprimer une réticence face à cet ouvrage (qui s'accompagne, en ligne sur le site de l'éditeur, d'un fichier de plusieurs centaines de pages de transcription des sources d'archives utilisées), ce serait la suivante : l'anthropologie du "désir masculin » qu'esquisse l'auteur reste inaboutie. Il semble placer cette étude du désir au cœur de sa recherche historique (p. 42). Mais certaines phrases semblent étrangement essentialistes: "le corps des jeunes filles, associé à la virginité, constitue (...) la quintessence du désir masculin» (p.126) ou, parlant d'un prêtre (p.113) «un aveu on ne peut plus clair d'homosexualité masculine puisque, même avec une femme, il pratique la sodomie ». 